\title{
Odorant Stimulation Promotes Survival of Rodent Olfactory Receptor Neurons via PI3KJAkt Activation and Bcl-2 Expression
}

\author{
So Yeun Kim ${ }^{1,4}$, Seung-Jun Yoo ${ }^{1,4}$, Gabriele V Ronnett ${ }^{1,2,3}$, Eun-Kyoung Kim ${ }^{1}$, and Cheil Moon, *
}

\begin{abstract}
Olfactory stimulation activates multiple signaling cascades in order to mediate activity-driven changes in gene expression that promote neuronal survival. To date, the mechanisms involved in activity-dependent olfactory neuronal survival have yet to be fully elucidated. In the current study, we observed that olfactory sensory stimulation, which caused neuronal activation, promoted activation of the phosphatidylinositol 3'-kinase (PI3K)/Akt pathway and the expression of $\mathrm{BCl}-2$, which were responsible for olfactory receptor neuron (ORN) survival. We demonstrated that Bcl-2 expression increased after odorant stimulation both in vivo and in vitro. We also showed that odorant stimulation activated Akt, and that Akt activation was completely blocked by incubation with both a PI3K inhibitor (LY294002) and Akt1 small interfering RNA. Moreover, blocking the PI3K/Akt pathway diminished the odorantinduced Bcl-2 expression, as well as the effects on odorant-induced ORN survival. A temporal difference was noted between the activation of Akt1 and the expression of $\mathrm{Bcl}-2$ following odorant stimulation. Blocking the PI3K/Akt pathway did not affect ORN survival in the time range prior to the increase in Bcl-2 expression, implying that these two events, activation of the PI3K pathway and Bcl-2 induction, were tightly connected to promote post-translational ORN survival. Collectively, our results indicated that olfactory activity activated PI3K/Akt, induced Bcl-2, and promoted long term ORN survival as a result.
\end{abstract}

\section{INTRODUCTION}

The stimulation of sensory systems plays essential roles in neuronal functions including information processing, dendritic and axonal refinement, synaptic plasticity, and survival of sen-

${ }^{1}$ Department of Brain \& Cognitive Sciences, Graduate School Daegu Gyeungbuk Institute of Science and Technology (DGIST), Daegu 711873, Korea, ${ }^{2}$ Department of Neuroscience, ${ }^{3}$ Department of Biological Chemistry, The Johns Hopkins University School of Medicine, Baltimore, MD 21205, USA, ${ }^{4}$ These authors contributed equally to this work.

${ }^{*}$ Correspondence: cmoon@ dgist.ac.kr

Received 10 February, 2015; accepted 12 March, 2015; published online 22 May, 2015

Keywords: Bcl-2, odorant, olfactory receptor neuron, PI3K/Akt, survival sory neurons (Feldman and Brecht, 2005; Jiao et al., 2006; Sale et al., 2014)., Sensory neuronal activation is especially critical for neuronal survival. The results of several studies have suggested that sensory deprivation impaired the survival of sensory neurons. In many cases, diminished sensory capacity due to aging, injuries, or neurodegenerative diseases leads to the death of sensory neurons (Aliani et al., 2013; Shaffer and Harrison, 2007). However, the processes and mechanisms involved in activity-dependent sensory neuronal survival have yet to be fully elucidated.

The phosphatidylinositol 3'-kinase (PI3K)/Akt pathway, which is activated by the generation of 3'-phosphorylated phosphoinositides, has been implicated as an important signaling pathway for survival in a wide variety of cell types [see review (Brunet et al., 2001)]. Moreover, increasing evidence suggests that the activation of different intracellular survival pathways, including the PI3K/Akt pathway, is regulated by variety of cellular activities (Horwood et al., 2006; Howlett et al., 2008; Uranga et al., 2013). In some cases, the prevention of neuronal cell death requires de novo gene expression, suggesting that some components or regulators of the anti-apoptotic machineries need to be newly synthesized before apoptosis occurs. For instance, Bcl-2, a critical component of the anti-apoptotic machineries, is up-regulated during the apoptosis of neurons [see review (Reed, 1994)]. Additionally, decreased Bcl-2 expression induces apoptosis by activating pro-apoptotic molecules, such as $\mathrm{BAX}$ and $\mathrm{BAD}$, whereas $\mathrm{Bcl}-2$ over-expression prevents cell death by inhibiting the apoptosis cascade [see review (Gross et al., 1999; Youle and Strasser, 2008)].

The mammalian olfactory system is an advantageous experimental model for studying the processes and mechanisms of activity-dependent cellular responses due to its cytoarchitecture, life cycle, and availability of in vivo and in vitro models (Ronnett and Moon, 2002). Odorant stimulation induces activation of various signaling cascades in olfactory receptor neurons (ORNs). In our previous study, deprivation of odorant stimulation through unilateral naris occlusion caused an up-regulation of apoptosis in olfactory epithelium (OE) neurons (Suh et al., 2006). Additionally, odorant stimulation enhances olfactory neuronal survival by activating the MAPK pathway, possibly resulting in Bcl-2 expression in ORNs (Watt et al., 2004; Yang et al., 2011). Although odorant stimulation appears to be involved in ORN survival, the underlying mechanisms remain unclear. In our present study, we investigated the ability of odorant stimulation to activate the PI3K/Akt pathway, induce sub- 
PI3K/Akt-Dependent Bcl-2 Expression and ORN Survival

So Yeun Kim et al.

sequent $\mathrm{Bcl}-2$ expression, and promote ORN survival using the olfactory system as a model.

\section{MATERIALS AND METHODS}

\section{Animals}

All experimental protocols were approved by the Institutional Animal Care and Use Committees of both DGIST and The Johns Hopkins University, and all applicable guidelines for the care and use of laboratory animals from the National Institutes of Health Guide were followed. Adult male mice (C57/BL6, 6-7 weeks old) and rat pups (Sprague Dawley, days 1-2 postpartum) were obtained from Harlan (USA) and KOATECH (Korea).

\section{Cell viability assay}

Cell viability was monitored by the calcein assay, which examined cells stained with calcein acetoxymethylester (AM) (C3100MP, Invitrogen, USA). Cultured ORNs were treated with a $10 \mu \mathrm{M}$ odorant mixture for $6 \mathrm{~h}$ and $18 \mathrm{~h}$, respectively, prior to incubation with calcein AM solution (final concentration $3 \mu \mathrm{M}$ ) for $30 \mathrm{~min}$. Cell viability was measured at wavelengths of 485 $\mathrm{nm}$ (excitation) and $535 \mathrm{~nm}$ (emission) using a microplate reader (SpectraMax Plus 384 Microplate Reader, Molecular devices, USA).

\section{Immunoblot analysis}

Immunoblots were performed according to methods of Laemmli (1970) and Towbin et al. (1979) with some modifications. ORN extracts were solubilized in boiling sample buffer (100 mM Tris$\mathrm{HCl}, 2 \%$ sodium dodecyl sulfate [SDS], $10 \% \beta$-mercaptoethanol, and $20 \%$ glycerol; $\mathrm{pH} 6.8$ ) and fractionated by SDS-polyacrylamide gel electrophoresis (10\% polyacrylamide). The proteins were transferred onto polyvinylidene difluoride membranes, which were incubated with primary antibodies overnight at $4^{\circ} \mathrm{C}$, followed by secondary antibody for one hr at room temperature. Immunoreactivity was detected using chemiluminescence reagents $(E C L$, Amersham, USA) and visualized after exposure to X-Omat film (Kodak).

\section{In situ hybridization}

In situ hybridization was performed as previously described with some modifications (Sung et al., 2002). Digoxigenin (DIG)labeled probes were used from identified clones. Bouin's fixed tissue sections of rat OE $(18 \mu \mathrm{m})$ were permeabilized with 1 $\mu \mathrm{g} / \mathrm{ml}$ Proteinase $\mathrm{K}$ (Boehringer Mannheim, USA) for $30 \mathrm{~min}$ at $37^{\circ} \mathrm{C}$ in Tris-buffered saline (TBS) containing $2 \mathrm{mM} \mathrm{CaCl}_{2}$ and post-fixed in Bouin's for 5 min at room temperature. After prehybridization at $37^{\circ} \mathrm{C}$ for 10 min with $2 \mathrm{X}$ saline-sodium citrate (SSC) containing $50 \%(\mathrm{v} / \mathrm{v})$ deionized formamide, sections were hybridized overnight at $65-72^{\circ} \mathrm{C}$ with prepared RNA probe in $50-100 \mu \mathrm{l}$ of hybridization buffer $(50 \%$ deionized formamide, $10 \%$ dextran sulfate, $2 \times$ SSC, $0.02 \%$ SDS, and $0.01 \%$ sheared salmon sperm DNA). On the following day, post-hybridization was carried out by immersion in 2x SSC, washing with SSC, and digestion of the single-stranded RNA probe by RNase A $(20 \mu \mathrm{g} / \mathrm{ml})$ for $30 \mathrm{~min}$ at $37^{\circ} \mathrm{C}$ in TNE buffer (10 mM Tris, 500 $\mathrm{mM} \mathrm{NaCl}, 5 \mathrm{mM}$ EDTA; $\mathrm{pH}$ 7.5). To visualize bound probe, sections were incubated with an anti-DIG Fab fragment (Boehringer Mannheim, USA) in TBS containing 10\% fetal calf serum for one $\mathrm{h}$ after being blocked with $10 \%$ fetal calf serum in TBS for $15 \mathrm{~min}$. Sections were then washed twice in TBS and incubated for $5 \mathrm{~min}$ in alkaline phosphatase (AP) buffer $(0.1 \mathrm{M}$ Tris-Cl, $0.1 \mathrm{M} \mathrm{NaCl}, 50 \mathrm{mM} \mathrm{MgCl}$; $\mathrm{pH} 9.5$ ). The color signal was developed in AP buffer containing $3.375 \mathrm{mg} / \mathrm{ml}$ nitro blue tetrazolium (Boehringer Mannheim, USA), $3.5 \mathrm{mg} / \mathrm{ml}$ 5-bromo4-chloro-3-indolyl phosphate (Boehringer Mannheim, USA), and $0.24 \mathrm{mg} / \mathrm{ml}$ levamisole. The colorimetric reaction was carried out at room temperature and terminated by washing with $\mathrm{dH} 2 \mathrm{O}$. The developed slides were coverslipped with Aquapolymount (Polysciences, USA). As a control experiment, sections are hybridized with identical amounts of sense cRNA.

\section{Northern blot}

For Northern blot analysis, total RNA was purified from ORNs with TRIzol reagent (Gibco-BRL, USA) as previously described with some modifications (Sung et al., 2002). Total RNA was loaded and electrophoresed in $1 \%$ agarose/2.2 M formaldehyde denaturing gel. The RNAs were transferred onto Hybond $\mathrm{N}+$ nitrocellulose membranes (Amersham Pharmacia Biotech, USA) using $10 \times$ SSC and cross-linked using a UV cross-linker (Stratagene, USA). Hybridization of the membranes was carried out with ${ }^{32} \mathrm{P}$-labeled cDNA probes under $5 \times$ SSC, $5 \times$ Denhardt's solution, $1 \%$ SDS, and $100 \mu \mathrm{g} / \mathrm{ml}$ denatured salmon sperm DNA. Membranes were then washed twice in $2 x$ $\mathrm{SSC} / 0.1 \% \mathrm{SDS}$ at $25^{\circ} \mathrm{C}, 0.2 \times \mathrm{SSC} / 0.1 \%$ SDS at $42^{\circ} \mathrm{C}$, and 0.1 $\times \mathrm{SSC} / 0.1 \% \mathrm{SDS}$ at $68^{\circ} \mathrm{C}$. Signals from the hybridized probe cDNAs were visualized by exposure to $X$-ray film.

\section{Primary culture of ORNs}

Primary cultures of ORNs were performed as previously described (Ronnett et al., 1991; 1993) with some modifications. Culture dishes (Falcon, USA) were coated with modified Eagle's medium containing D-valine (MDV, Gibco-BRL, USA) and $25 \mu \mathrm{g} / \mathrm{ml}$ laminin (Collaborative Research, USA). ORNs were plated at a density of $6 \times 10^{5}$ cells $/ \mathrm{cm}^{2}$, and then fed with MDV containing $15 \%$ dialyzed fetal calf serum (Gibco$\mathrm{BRL}$, USA), gentamycin, kanamycin, and $25 \mathrm{ng} / \mathrm{ml}$ nerve growth factor (NGF) on each day. The concentration of NGF in the feeding medium was changed to $2.5 \mathrm{ng} / \mathrm{mL}$ two days prior to use.

\section{Pharmacological manipulation of signaling cascades} LY294002 (Invitrogen, USA), a PI3K specific-inhibitor, in dimethyl sulfoxide stock was used in this study. Following preincubation in medium containing LY294002 at the final concentration of $50 \mu \mathrm{M}$ for $30 \mathrm{~min}$, ORNs were incubated for designated durations.

\section{Unilateral naris occlusion}

Unilateral sensory deprivation was performed following the method of Cummings with modification (Cummings et al., 1997; Suh et al., 2006). Constructed nasal tubes (PE50, $0.965 \mathrm{~mm}$ outer diameter, Becton Dickinson, USA) were inserted into the right nostrils of male adult C57BL/6J mice (8 weeks old) from Jackson Laboratories (USA) under anesthesia using Xylaket. After recovering from the anesthetic, mice were raised under normal conditions until being sacrificed.

\section{RESULTS}

Odorant stimulation induces the anti-apoptotic protein Bcl-2 $\mathrm{Bcl}-2$ is a well-established anti-apoptotic protein known to promote neuronal survival (Reed, 1994; Youle and Strasser, 2008). We previously showed that $\mathrm{Bcl}-2$ induced by leukemia inhibitory factor acted as an anti-apoptotic protein and promoted olfactory neuronal survival (Moon et al., 2009). Because odorant stimulation appears to promote ORN survival (Watt et al., 2004), we examined whether odorant stimulation affected the expression 

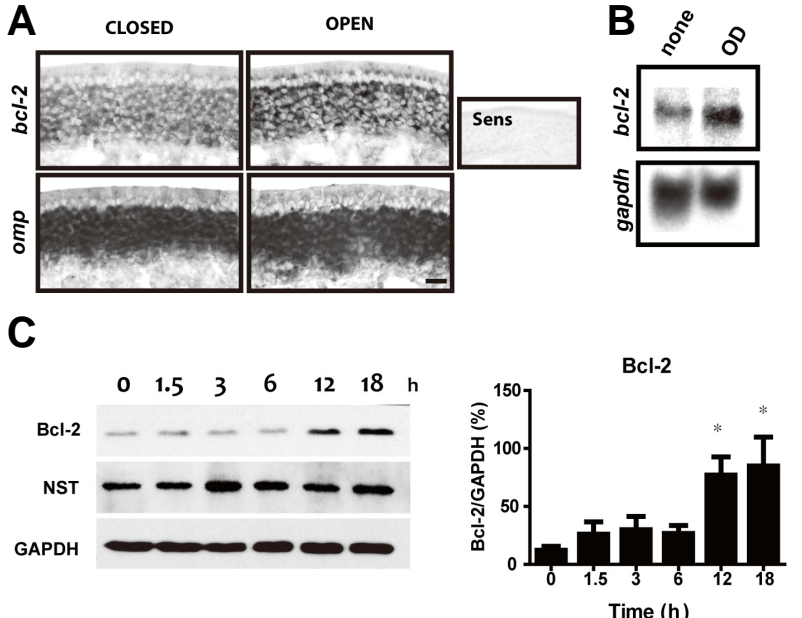

Fig. 1. (A) In situ hybridization of $b c l-2$ mRNA in mouse OE. $b c l-2$ mRNA expression was visualized in the presence (OPEN) or absence (CLOSED) of odorant stimuli $(1 \mathrm{mM})$ for $6 \mathrm{~h}$. omp (an olfactory marker protein) mRNA was used as a control. Scale bars $=100 \mu \mathrm{m}$. (B) Northern blot of bcl-2 mRNA and gapdh mRNA in ORN cultures. ORNs were exposed to $10 \mu \mathrm{M}$ odorants for $6 \mathrm{~h}$. (C) Immunoblot of Bcl-2, NST ( $\beta$-tubulin III), and GAPDH in ORN cultures. Cells were treated with $10 \mu \mathrm{M}$ odorants and sampled at a specific time $(0,1.5,3,6,12$, or $18 \mathrm{~h})$. Results from the quantitative analysis of $\mathrm{Bcl}-2$ expression induced by odorants from three independent experiments are summarized on the right. Quantification of each protein expression level was measured by stereological analysis using the ImageJ program, and compared to GAPDH expression. All data are presented as mean \pm SEM. One-way analysis of variance (ANOVA), followed by Dunnett's post hoc test, was performed. ${ }^{*} \mathrm{P}<0.05$ denotes statistical significance.

of $\mathrm{Bcl}-2$ in a manner that would facilitate olfactory neuronal survival. Mice with unilateral naris occlusions and subsequent olfactory stimulus deprivation were exposed to a $1 \mathrm{mM}$ odorant mixture (2-isobutyl-3-methoxypyrazine, citralva, and isovaleric acid) for $6 \mathrm{~h}$. Then, the OE of the mice was examined using an in situ hybridization analysis. In the OE, bcl-2 mRNA was present in most mature layers, which correlated well with omp mRNA-expressing layers, but not in the basal cell layer (Fig. 1A). The open side displayed a clear increase in bcl-2 mRNA expression in the OE, suggesting that odorant stimulation may induce bcl-2 mRNA expression. In order to examine the $\mathrm{Bcl}-2$ expression attributable to odorant stimulation in ORNs, we examined $\mathrm{Bcl}-2$ expression in dissociated cultures of ORNs under odorant exposure conditions. Northern blot analysis revealed that $b c l-2$ mRNA expression was clearly increased after treatment with vehicle and odorant mixtures at $10 \mu \mathrm{M}$ for $6 \mathrm{~h}$ (Fig. 1B). We also confirmed an increase in Bcl-2 protein levels in a time dependent manner under the same conditions (Fig. 1C). After $12 \mathrm{~h}$ of treatment, odorants induced significant up-regulation of $\mathrm{Bcl}-2$ without changes in neuron-specific tubulin (NST) expression levels, indicating that there was no increase in number of neurons (Fig. 1C). Based on our in vivo and in vitro experiments, we suggest that odorant stimulation increases the expression of $\mathrm{BCl}-2 \mathrm{mRNA}$ and protein levels after $12 \mathrm{~h}$ of exposure to odorant stimulation.
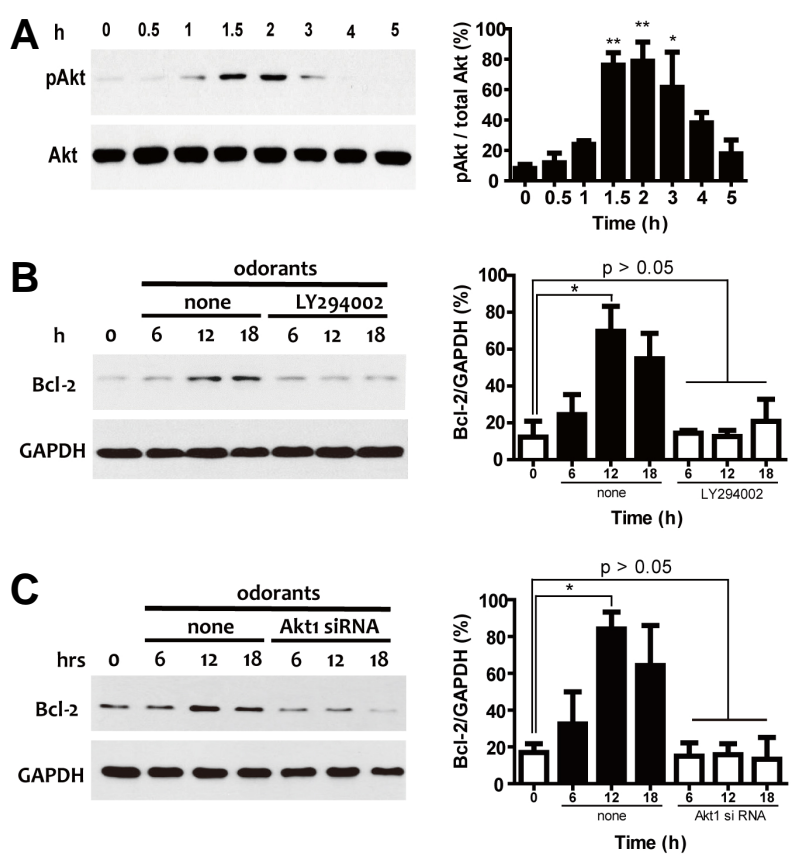

Fig. 2. (A) Analysis of PI3K/Akt pathway activation by odorants. ORNs were treated with $10 \mu \mathrm{M}$ odorants and sampled at a specific time $(0,0.5,1,1.5,2,3,4$, or $6 \mathrm{~h})$. Activation of Akt was measured using antibodies against phospho-Akt (pAkt) and total Akt (Akt). Quantification of protein expression levels was determined by stereological analysis using the ImageJ analysis program. Equal loading of samples was confirmed by monitoring the total Akt protein level. (B) Pharmacological blocking of Akt activation. ORNs were incubated in $50 \mu \mathrm{M}$ LY294002, a PI3K inhibitor. Akt activation was clearly blocked by LY294002. Immunoblots for Bcl-2 and GAPDH in the presence of $50 \mu \mathrm{M}$ LY294002 at specific times $(0,6,12$, and $18 \mathrm{~h})$ were visualized. Results of the quantitative analysis of Bcl-2 expression by odorants in the presence or absence of LY294002 for PI3K were summarized. (C) Translational blocking of Akt activation. ORNs were incubated with siRNA for Akt1 for $18 \mathrm{~h}$. Akt activation was clearly blocked by incubation with siRNA. Immunoblots for Bcl-2 and GAPDH after incubation with siRNA for Akt1 at specific times $(0,6,12$, and $18 \mathrm{~h})$ were visualized. Results of the quantitative analysis of $\mathrm{Bcl}-2$ expression by odorants after incubation with siRNA for Akt1 were summarized. All data are presented as mean \pm SEM. One-way ANOVA, followed by Dunnett's post hoc test, was performed. ${ }^{*} P<0.05$ and ${ }^{* *} P<0.01$ denote statistical significance.

Odorant stimulation activates the PI3K/Akt pathway and promotes PI3K/Akt pathway-dependent Bcl-2 expression To investigate additional mechanisms of $\mathrm{Bcl}-2$ expression in the response to sensory stimuli, we focused on an examination of the activation of the PI3K/Akt pathway by odorant stimulation (Spehr et al., 2002; Ukhanov et al., 2010; 2011). To explore the activation of the PI3K/Akt pathway by odorant stimulation, we investigated an aspect of the downstream activation of the $\mathrm{PI}$ IK/Akt pathway, a serine/threonine protein kinase Akt (protein kinase B). Strikingly, odorant stimulation induced transient activation of Akt at very early time points (1.5-3 h; Fig. 2A).

To examine the relationship between Akt and Bcl-2 expression in ORNs, we blocked the activation of the PI3K/Akt pathway by either preincubating with LY294002 $(50 \mu \mathrm{M})$, a specific inhibitor of PI3K, or knocking-down Akt expression using a 

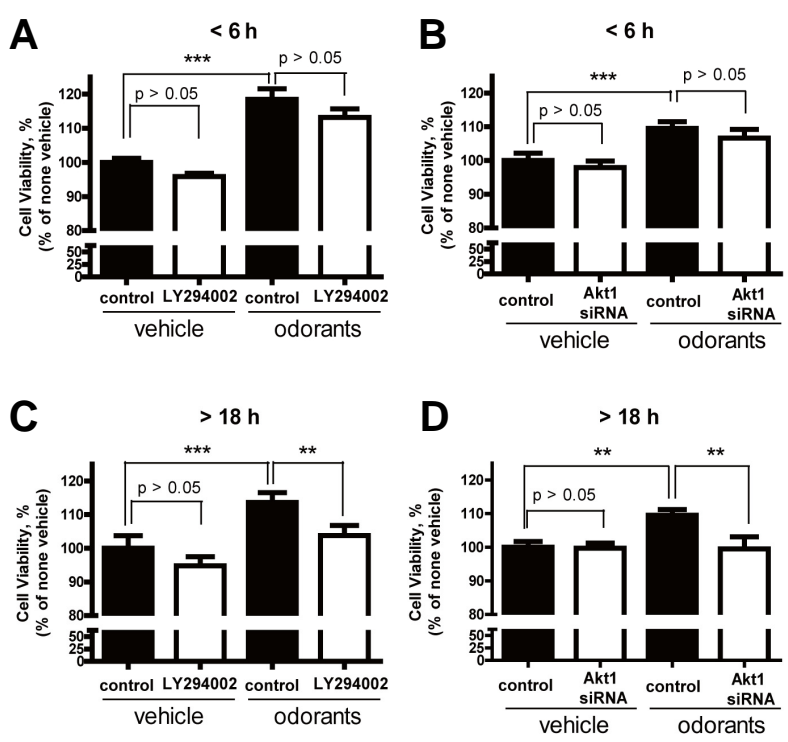

Fig. 3. (A, B) Neuroprotective effects of Akt activation by odorant stimulation in the early stage. In the presence of $10 \mu \mathrm{M}$ odorants, ORNs were co-incubated for $6 \mathrm{~h}$ in the presence or absence of $(\mathrm{A}) 50$ $\mu \mathrm{M}$ LY294002 or (B) siRNA for Akt1, respectively. (C, D) Neuroprotective effects of Akt activation by odorant stimulation in the late stage. In the presence of $10 \mu \mathrm{M}$ odorants, ORNs were coincubated for $18 \mathrm{~h}$ in the presence or absence of (C) $50 \mu \mathrm{M}$ LY294002 or (D) siRNA for Akt1, respectively. Cell viability was assessed by the calcein assay. Data are expressed as percent of value in untreated control cultures (serum free condition). Data are presented as means \pm SEM from three independent experiments. One-way ANOVA, followed by Dunnett's post hoc test, was performed. ${ }^{* *} \mathrm{P}<$ 0.01 and ${ }^{\star \star \star} P<0.001$ denote statistical significance.

small interfering RNA (siRNA) for Akt1, which is a major component of Akt (data not shown). PI3K inhibition using LY294002 blocked odorant stimulation-promoting Bcl-2 induction, implying that odorant stimulation-induced $\mathrm{Bcl}-2$ expression may be regulated by the PI3K/Akt pathway (Fig. 2B). Additionally, inhibition of Akt1 expression using Akt1 siRNA also blocked the odorant stimulation-promoting $\mathrm{Bcl}-2$ induction, indicating that odorant stimulation-induced $\mathrm{Bcl}-2$ expression is regulated by Akt1 (Fig. 2C). Although a temporal difference in the activation of Akt and the expression of Bcl-2 was observed, Akt activation and Bcl-2 expression by odorant stimulation may be deeply connected.

Odorant stimulation promotes long-term ORN survival via the PI3K/Akt pathway

Next, we examined whether the PI3K/Akt pathway activated by odorant stimulation would affect ORN survival by using dissociated cultures of ORNs. To detect a correlation between the activation of the PI3K/Akt pathway and Bcl-2 expression in ORN survival, we examined cell viability during the $6 \mathrm{~h}$ that represented PI3K/Akt pathway activation without Bcl-2 expression, and the $18 \mathrm{~h}$ that represented the period of induced Bcl-2 expression. Cultured ORNs were treated with a $10 \mu \mathrm{M}$ odorant mixture for 6 and $18 \mathrm{~h}$, respectively, and cells were subjected to the calcein assay. When ORN cultures were incubated in the presence of odorants, cell viability significantly increased over both time courses. We also tested the role of the PI3K/Akt pathway in the odorant stimulation-promoted ORN survival. The
ORN cultures were treated in media containing LY294002 (50 $\mu \mathrm{M})$, or were incubated with siRNA for Akt1 $24 \mathrm{~h}$ prior to the odorant treatment to inhibit the PI3K/Akt pathway. Inhibition of both PI3K and Akt1 significantly decreased the odorant stimulation-induced ORN survival at $18 \mathrm{~h}$ (Figs. 3C and 3D). Interestingly, at 6 hours, inhibition of either PI3K or Akt1 did not seem to affect the viability of ORNs (Figs. $3 A$ and $3 B$ ). To confirm the correlation between Akt activation and late expression of Bcl-2, we showed that the survival effect of Akt activated by odorant exposure was only involved at the later time point $(>18 \mathrm{~h})$ as opposed to the earlier time point $(<6 \mathrm{~h})$. This result is well correlated with delayed $\mathrm{Bcl}-2$ expression $(<12 \mathrm{~h}$ ) after odorant stimulation. Our data suggest that odorant stimulation affects long-term ORN survival via PI3K/Akt dependent pathways, but is not involved in short-term ORN survival.

\section{DISCUSSION}

Our study demonstrated that olfactory sensory stimulation, which induced neuronal activation, promoted activation of the $\mathrm{PI}$ 3K/Akt pathway, subsequent expression of $\mathrm{Bcl}-2$, and longterm ORN survival. Although we observed a time difference between the activation of the PI3K/Akt pathway and the increased expression of $\mathrm{Bcl}-2$, we demonstrated that these two events were tightly connected. The results of our experiments suggested that olfactory activity activated the PI3K/Akt pathway to induce Bcl-2 expression and promote long term ORN survival.

The results of previous studies have suggested that sensory stimuli induce survival of sensory neurons though increased anti-apoptotic Bcl-2 expression (Moon et al., 2009). In the current study, we confirmed Bcl-2 expression in ORNs following odorant stimulation in vivo and in vitro, and our results implied that the Bcl-2-related survival effect of ORNs mediated by odorant stimulation may occur regardless of the retrograde survival signals derived from the olfactory bulb (OB). Our in situ hybridization results suggested that bcl-2 mRNA expression increased in the omp mRNA-expressing layer where mature ORNs reside in the OE. Because we were able to demonstrate $\mathrm{Bcl}-2$ expression in dissociated ORN cultures more than $12 \mathrm{~h}$ after exposure to odorants, we concluded that odorant stimulation directly promoted $\mathrm{Bcl}-2$ induction. Collectively, this delayed response in $\mathrm{Bcl}-2$ expression following odorant stimulation in the ORNs in the mature OE implied that Bcl-2 induction may affect the long-term survival of ORNs in the OE. Therefore, we precluded the possibility that the long-term effects of odorant stimulation were mediated by the effects of activities derived from the OB. Importantly, we observed bcl-2 mRNA upregulation even in the sustentacular cells upon odorant stimulation, implying that odorant stimulation may affect $b c l-2$ mRNA expression in the sustentacular cells, most likely in an indirect manner.

One of the main areas of interests in the present study was the activation of the PI3K/Akt pathway upon odorant stimulation, and the connection between this activation and the antiapoptotic effects that followed $\mathrm{Bcl}-2$ expression. In previous studies, the PI signaling controlled by the PI3K/Akt pathway showed important functions in ORN signaling by regulating the activity of ion channels and transporters (Spehr et al., 2002; Ukhanov et al., 2010; 2011). In the current study, we showed Akt activation in a time-dependent manner following odorant exposure in cultured ORNs. The activated PI3K/Akt pathway may exert its influence on the regulation of various neuronal events, synaptic plasticity, and neurite outgrowth, through biosynthesis (Bruel-Jungerman et al., 2009; Hou and Klann, 2004; 
Jaworski et al., 2005) and the activation of translation machinery, which induces expression of related downstream effectors predominantly involved in cell survival through the regulation of pro-apoptotic/anti-apoptotic proteins (Howlett et al., 2008; Uranga et al., 2013). Compared to Bcl-2 expression, Akt activation was induced at an earlier time point (1-3 h) following odorant exposure. Despite this discrepancy in the time courses of $\mathrm{PI} 3 \mathrm{~K} / \mathrm{Akt}$ pathway activation and $\mathrm{Bcl}-2$ induction, we demonstrated a close relationship between $\mathrm{Bcl}-2$ expression and the $\mathrm{PI} 3 \mathrm{~K} / \mathrm{Akt}$ signal pathway in ORNs, as $\mathrm{Bcl}-2$ expression was completely blocked by pharmacological inhibition of PI3K and translational blockage of Akt1. Additionally, cell viability was well correlated with activation of the PI3K/Akt pathway and Bcl-2 expression. There may be no survival effect derived from activation of the PI3K/Akt pathway at earlier time points; however, increased ORN survival at the later time points following odorant exposure may have been attributable to activation of the PI3K/Akt pathway and subsequent expression of Bcl-2. Our results indicated that the PI3K/Akt pathway was necessary to induce delayed Bcl-2 expression ( $<12 \mathrm{~h}$ ), likely dependent on gene expression triggered by activation of transcription factors which can be induced by odorant stimulation (Watt et al., 2004).

Although these observations emphasize the importance of neuronal activation in sensory neuronal survival, the entirety of the mechanisms involved remain to be elucidated. The results of the current study revealed important aspects of these complex mechanisms. Olfactory sensory stimulation simultaneously promoted ORNs survival as a long-term cellular response through the intrinsic mechanisms of sensory neurons. Among the several neuroprotective signaling pathways mediated by neural activation, odorant-induced activation of the PI3K/Akt pathway was found to be responsible for promoting sensory neural survival associated with the expression of $\mathrm{Bcl}-2$ by intrinsic mechanisms.

\section{ACKNOWLEDGMENTS}

This work was supported by the DGIST R\&D Program of the Ministry of Science, ICT and Future Planning (15-BD-0402).

\section{REFERENCES}

Aliani, M., Udenigwe, C.C., Girgih, A.T., Pownall, T.L., Bugera, J.L., and Eskin, M.N. (2013). Aroma and taste perceptions with Alzheimer disease and stroke. Crit. Rev. Food Sci. Nutr. 53, 760-769.

Bruel-Jungerman, E., Veyrac, A., Dufour, F., Horwood, J., Laroche, S., and Davis, S. (2009). Inhibition of PI3K-Akt signaling blocks exercise-mediated enhancement of adult neurogenesis and synaptic plasticity in the dentate gyrus. PLoS One 4, e7901.

Brunet, A., Datta, S.R., and Greenberg, M.E. (2001). Transcriptiondependent and -independent control of neuronal survival by the PI3K-Akt signaling pathway. Curr. Opin. Neurobiol. 11, 297-305.

Cummings, D.M., Knab, B.R., and Brunjes, P.C. (1997). Effects of unilateral olfactory deprivation in the developing opossum, Monodelphis domestica. J. Neurobiol. 33, 429-438.

Feldman, D.E., and Brecht, M. (2005). Map plasticity in somatosensory cortex. Science 310, 810-815.

Gross, A., McDonnell, J.M. and Korsmeyer, S.J. (1999). BCL-2 family members and the mitochondria in apoptosis. Genes Dev. 13, 1899-1911.

Horwood, J.M., Dufour, F., Laroche, S., and Davis, S. (2006). Signalling mechanisms mediated by the phosphoi-nositide 3kinase/Akt cascade in synaptic plasticity and memory in the rat. Eur. J. Neurosci. 23, 3375-3384.

Hou, L., and Klann, E. (2004). Activation of the phosphoinositide 3-
kinase-Akt-mammalian target of rapamycin signaling pathway is required for metabotropic glutamate receptor-dependent longterm depression. J. Neurosci. 24, 6352-6361.

Howlett, E., Lin, C.C., Lavery, W., and Stern, M. (2008). A PI3-kinasemediated negative feedback regulates neuronal excitability. PLoS Genet. 4, e1000277.

Jaworski, J., Spangler, S., Seeburg, D.P., Hoogenraad, C.C., and Sheng, M. (2005). Control of dendritic arborization by the phosphoinositide-3'-kinase-Akt-mammalian target of rapamycin pathway. J. Neurosci. 25, 11300-11312.

Jiao, Y., Zhang, C., Yanagawa, Y., and Sun, Q.Q. (2006). Major effects of sensory experiences on the neocortical inhibitory circuits. J. Neurosci. 26, 8691-8701.

Laemmli, U.K. (1970). Cleavage of structural proteins during the assembly of the head of bacteriophage T4. Nature 227, 680-685

Moon, C., Liu, B.Q., Kim, S.Y., Kim, E.J., Park, Y.J., Yoo, J.Y., Han, H.S., Bae, Y.C., and Ronnett, G.V. (2009). Leukemia inhibitory factor promotes olfactory sensory neuronal survival via phosphoinositide 3-kinase pathway activation and Bcl-2. J. Neurosci. Res. 87, 1098-1106.

Reed, J.C. (1994). Bcl-2 and the regulation of programmed cell death. J. Cell Biol. 124, 1-6.

Ronnett, G.V., and Moon, C. (2002). G proteins and olfactory signal transduction. Annu. Rev. Physiol. 64, 189-222.

Ronnett, G.V., Hester, L.D., and Snyder, S.H. (1991). Primary culture of neonatal rat olfactory neurons. J. Neurosci. 11, 1243-1255.

Ronnett, G.V., Cho, H., Hester, L.D., Wood, S.F., and Snyder, S.H. (1993). Odorants differentially enhance phosphoino-sitide turnover and adenylyl cyclase in olfactory receptor neuronal cultures. J. Neurosci. 13, 1751-1758.

Sale, A., Berardi, N., and Maffei, L. (2014) Environment and brain plasticity: towards an endogenous pharmacotherapy. Physiol. Rev. 94, 189-234.

Shaffer, S.W., and Harrison, A.L. (2007). Aging of the somatosensory system: a translational perspective. Phys. Ther. 87, 193-207.

Spehr, M., Wetzel, C.H., Hatt, H., and Ache, B.W. (2002). 3phosphoinositides modulate cyclic nucleotide signaling in olfactory receptor neurons. Neuron 33, 731-739.

Suh, K.S., Kim, S.Y., Bae, Y.C., Ronnett, G.V., and Moon, C. (2006). Effects of unilateral naris occlusion on the olfactory epithelium of adult mice. Neuroreport 17, 1139-1142.

Sung, Y.K., Moon, C., Yoo, J.Y., Moon, C., Pearse, D., Pevsner, J., and Ronnett, G.V. (2002). Plunc, a member of the secretory gland protein family, is up-regulated in nasal respiratory epithelium after olfactory bulbectomy. J. Biol. Chem. 277, $12762-12769$.

Towbin, H., Staehelin, T., and Gordon, J. (1979). Electrophoretic transfer of proteins from polyacrylamide gels to nitrocellu-lose sheets: procedure and some applications. Proc. Natl. Acad. Sci. USA 76, 4350-4354.

Ukhanov, K., Corey, E.A., Brunert, D., Klasen, K., and Ache, B.W. (2010). Inhibitory odorant signaling in Mammalian olfactory receptor neurons. J. Neurophysiol. 103, 1114-1122.

Ukhanov, K., Brunert, D., Corey, E.A., and Ache, B.W. (2011). Phosphoinositide 3-kinase-dependent antagonism in mammalian olfactory receptor neurons. J. Neurosci. 31, 273-280.

Uranga, R.M., Katz, S., and Salvador, G.A. (2013). Enhanced phosphatidylinositol 3-kinase (PI3K)/Akt signaling has pleiotropic targets in hippocampal neurons exposed to iron-induced oxidative stress. J. Biol. Chem. 288, 19773-19784.

Watt, W.C., Sakano, H., Lee, Z.Y., Reusch, J.E., Trinh, K., and Storm, D.R. (2004). Odorant stimulation enhances survival of olfactory sensory neurons via MAPK and CREB. Neuron 41, 955-967.

Yang, D., Liu, X., Zhang, R., Cheng, K., Mu, J., Fang, L., and Xie, P. (2011). Increased apoptosis and different regulation of proapoptosis protein bax and anti-apoptosis protein bcl-2 in the olfactory bulb of a rat model of depression. Neurosci. Lett. 504 18-22.

Youle, R.J., and Strasser, A. (2008). The BCL-2 protein family: opposing activities that mediate cell death. Nat. Rev. 9, 47-59. 